\title{
Celiac disease (CD), ulcerative colitis (UC), and primary sclerosing cholangitis (PSC) in one patient: a family study
}

\author{
V. Cadahía, L. Rodrigo, D. Fuentes, S. Riestra, R. de Francisco and M. Fernández ${ }^{1}$ \\ Servicies of Digestive Diseases and ${ }^{1}$ Pathology. Hospital Universitario Central de Asturias. Oviedo, Spain
}

\begin{abstract}
We discuss the case of a 17-year-old male who at the age of 7 was diagnosed with celiac disease (CD) together with ulcerative colitis (UC) and primary sclerosing cholangitis (PSC). The patient was treated with gluten-free diet and immunosuppressive drugs (azathioprine), and currently remains asymptomatic.

The patient's younger, 12-year-old sister was diagnosed with $\mathrm{CD}$ when she was 1.5 years old, and at 7 years she developed type-I diabetes mellitus, which was difficult to control.

A family study was made, and both parents were found to be affected with silent CD. All were DQ2 (+). In relation to the case and family study, we provide a series of comments related to CD and its complications.
\end{abstract}

Key words: Celiac disease (CD). Ulcerative colitis (UC). Primary sclerosing cholangitis (PSC). Family study.

Cadahía V, Rodrigo L, Fuentes D, Riestra $S$, de Francisco $R$, Fernández M. Celiac disease (CD), ulcerative colitis (UC), and primary sclerosing cholangitis (PSC) in one patient: a family study. Rev Esp Enferm Dig 2005; 97: 907-913.

\section{INTRODUCTION}

Celiac disease $(\mathrm{CD})$ is a process which presents in genetically predisposed individuals -generally HLA-DQ2 $(+)$ in around $90 \%$ of cases or HLA-DQ8 (+) in the re-

Recibido: 27-05-05.

Aceptado: 31-05-05.

Correspondencia: Valle Cadahía Rodrigo. Servicio de Aparato Digestivo. Hospital Universitario Central de Asturias. C/ Celestino Villamil, s/n. 33006 Oviedo. Fax: 985273 614. e-mail: vallecadahia@terra.es maining 7-10\% of cases - as a consequence of an altered immune response to an extrinsic factor, namely gliadin, a protein contained in the flour of most cereals except corn.

In CD patients it is relatively frequent to find the presence of associated diseases such as type I diabetes, herpetiformis dermatitis, and autoimmune thyroiditis, among others (1-3).

The finding of moderate familial aggregation in patients with CD is normal. This ranges from $10 \%$ to $20 \%$ of cases (4), and family members may be asymptomatic or have atypical forms resulting in no search for cases, thus remaining undiagnosed for long periods of time.

Primary sclerosing cholangitis (PSC) is a liver disease of autoimmune nature in which genetic, acquired, or both factors are involved. Its association with other diseases is well demonstrated, most commonly including inflammatory bowel disease (IBD), mainly ulcerative colitis (UC) (in $70 \%$ of cases).

We present the case of a patient with $\mathrm{CD}$ associated with UC and PSC, all of which began in infancy, and in whose family study we found different presentation forms together with other associated diseases in the father and a sister, both of them affected.

\section{CASE STUDY}

A 17-year-old patient who was initially referred to our center from a local hospital some 10 years ago, at the age of 7 , because of a persistent alteration of liver function tests for one year then.

His parents reported the existence of various intermittent diarrhea episodes since 6 months of age, which had been classified as irritable bowel syndrome (IBS).

No previous history of blood tranfusions, episodes of acute hepatitis, jaundice, or pruritus were reported. Physical examination was negative, and the patient had a normal development for his age. 
A CBC was normal, and liver function tests showed a mixed pattern of cytolysis plus dissociated cholestasis, with $\mathrm{AST}=133(\mathrm{n}<40) \mathrm{IU} / \mathrm{L} ;$ ALT = $211(\mathrm{n}<40) \mathrm{IU} / \mathrm{L}$; $\mathrm{AP}=1.365(\mathrm{n}<180) \mathrm{IU} / \mathrm{L} ; \mathrm{GGT}=268(\mathrm{n}<50) \mathrm{IU} / \mathrm{L} ;$ total bilirubin $=2.2(\mathrm{n}<1) \mathrm{mg} / \mathrm{dl}$.

The screening for the various viral markers of hepatitis (A, B, C, CMV, EB, HS and VZ), and anti-toxoplasm antibodies were all negative. Non-organ specific auto-antibodies (ANAs, AMAs, AML, and anti-LKM1), and the early detection of metabolic disease (hemochromatosis, Wilson's disease, $\alpha_{1}$-antitripsin deficiency) were also negative.

Laboratory studies showed the presence of ANAs (+) at low titres (1/40); EMAs (+) (1/80); anti-reticulin antibodies (+) (1/160), and p-ANCA (+) (1/320), all at medium-high titres. The remaining laboratory tests were normal.

For the study of diarrhea and the presence of positive serological markers of CD, an intestinal biopsy with a Watson-Crosby capsule was made. The histological study showed the presence of severe duodenal villi atrophy, with crypt hypertrophy together with the presence of severe lymphocytic infiltration in the submucosa, thus confirming the diagnosis of CD classified as Marsh stage 3c (Fig. 1A).

A sigmoidoscopy was performed and demonstrated the presence of a friable, edematous mucosa which bled easily on contact with the endoscope, multiple erosions, and superficial ulcerations. Colonic biopsies demonstrated the presence of chronic inflammatory infiltration of the submucosa, with the presence of crypt abscesses and epithelial erosions, this being diagnosed as moderate UC (Fig. 1B).

A liver biopsy was performed, in which the presence of a moderate portal and lobulillar inflammatory infiltrate with severe porto-portal and periductular fibrosis in the form of "onion layers" was seen, together with intense ductular proliferation, this being diagnosed as PSC (Fig. 1C).
In order to make a topographic diagnosis and for extension assessment an endoscopic retrograde cholangiopancreatography (ERCP) was made, which showed the presence of an intrahepatic "winter aspect" of the biliary tree in the canalicular branches, and with "beaded ducts", together with a preserved extra-hepatic duct, thus confirming a predominance of intrahepatic involvement.

The patient was started on a gluten-free diet (GFD) and received ursodeoxycholic acid (900 mg/day) and 5ASA (2 g/day). He remained asymptomatic, with improved liver function tests, for 2 years. The patient later presented with an episode of acute cholangitis, which responded favourably to antibiotic treatment at home, and a relapse of $\mathrm{UC}$, which required admittance to hospital; azathioprine (150 mg/day) was then initiated, which is currently maintained. Two years ago, an upper GI endoscopy was performed and showed normal findings. Duodenal biopsies were made and were normal.

The patient is currently completely asymptomatic, living a normal life, and attending our outpatient clinic every 6 months.

\section{FAMILY STUDY}

One year after the index case was diagnosed, his younger sister, at 1.5 years of age, presented with diarrhea, abdominal pain, and vomiting, together with weight loss and growth retardation. Serological studies and jejunal biopsies were made, and the diagnosis of celiac disease (CD) in its classical form was confirmed; duodenal biopsies showed a moderate degree of atrophy (Marsh's stage 3b). A GFD was begun and a good clinical-laboratory response was seen. Six years later, at the age of 7.5 years, this patient presented with type I diabetes mellitus,

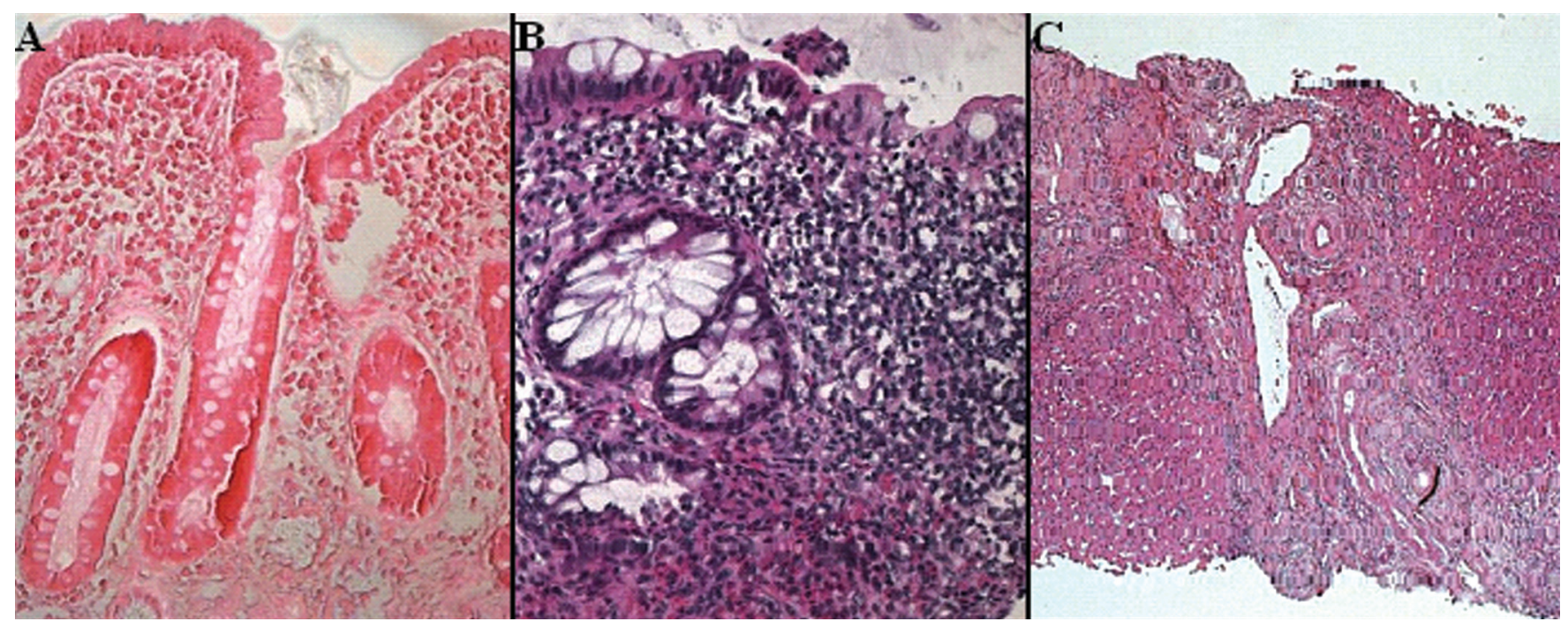

Fig 1.- A: villous atrophy; $B$ : ulcerative colitis; $C$ : primary sclerosing cholangitis.

$A$ : atrofia vellositaria; $B$ : colitis ulcerosa; $C$ : colangitis esclerosante primaria. 


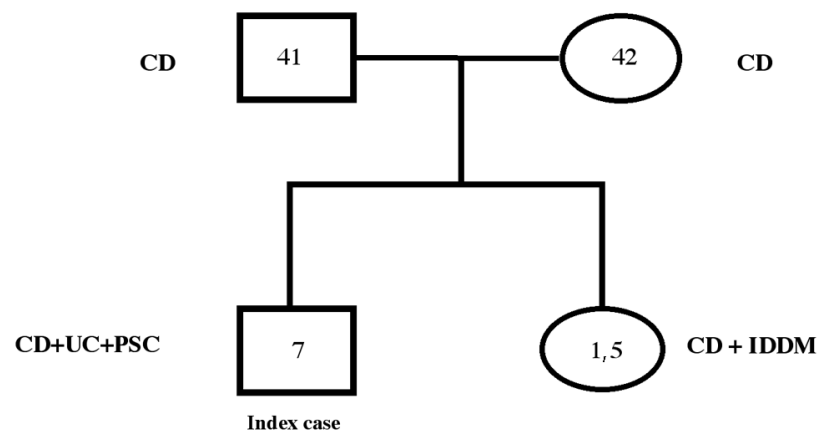

Fig. 2.- Familial tree (CD: celiac disease; UC: ulcerative colitis; PSC: primary sclerosing cholangitis; IDDM: type-I diabetes mellitus).

Árbol familiar (CD: enfermedad celiaca; UC: colitis ulcerosa; PSC: colangitis esclerosante primaria; IDDM: diabetes mellitus tipo 1).

which proved difficult to control. Three daily doses of rapid insulin are required for adequate control.

With these findings in a brother and sister, a family study was begun. Both were completely asymptomatic. Laboratory-wise, the mother had slight sideropenia. The father had normal laboratory tests, with a positive serological profile for $\mathrm{CD}$ and moderate duodenal villi atrophy (Marsh's stage 3b). Both were diagnosed with silent $\mathrm{CD}$ and started on a GFD. They continue to be asymptomatic without associated diseases, and do not currently show any laboratory changes. The findings in the family, laboratory, genetic, and histological studies show that all members of this family were affected, all four of them being DQ2 (+). The mother had a negative serology for $\mathrm{CD}$, and showed no signs of villous atrophy at the duodenal biopsy, only a mild inflammatory infiltrate of the submucosa (Marsh's stage 2) (Table I).

\section{DISCUSSION}

The association between UC and PSC is well documented, and it is estimated that $3-5 \%$ of patients with UC may develop PSC along their lives (4).

However, the association between CD and PSC is much lower, with an estimated mean frequency of around $1.5 \%(5)$.

An association between CD and autoimmune chronic cholestatic liver diseases such as primary biliary cirrhosis (PBC) and autoimmune cholangitis (AIC), which presents with an intermediate frequency between the abovementioned figures, exists and is estimated to be around $3.5 \%$ of cases $(6)$.

Only a few cases have been described thus far on this rare association between $\mathrm{CD}, \mathrm{UC}$ and PSC. In the majority of cases UC precedes by several years the diagnosis of the other two diseases; this is different in our case, as the three conditions were diagnosed virtually simultaneously.

For this reason, above all in patients with $\mathrm{CD}$, we recommend the use of an active search for associated diseases, not only digestive but also systemic conditions. This appears to be due to the fact that various processes share the same HLA class II haplotype, which could probably be the main predisposing factor for the development of other concomitant diseases autoimmune in nature $(7,8)$.

It has been speculated whether the delay in making the diagnosis of $C D$ and therefore in the initiation of a gluten-free diet (GFD) may favour the appearance of associated diseases, although this hypothesis is highly controversial and at present has not been clarified $(9,10)$.

A study carried out with the aim of estimating the prevalence of $\mathrm{CD}$ in children and young people with type-I diabetes mellitus and the influence of its early diagnosis in the prevention of a later development of $\mathrm{CD}$,

Table I. Demographic, clinical, laboratory, serologic, genetic, and pathological characteristics of the family study

\begin{tabular}{|c|c|c|c|c|c|c|}
\hline Family relationship & Age/gender & Clinical & Biochemical & Serological & $H L A$ & $\begin{array}{l}\text { Intestinal biopsy } \\
\text { Marsh stage }\end{array}$ \\
\hline Index case & $7 / \mathrm{M}$ & Diarrhea & Hypertransaminasemia & $\begin{array}{c}\text { AGA }(-) \\
\text { AEM } 1 / 80 \\
\text { AR } 1 / 160\end{array}$ & DQ2 (+) & $\begin{array}{l}\text { Subtotal atrophy } \\
(3 c)\end{array}$ \\
\hline Sister & $1.5 / F$ & $\begin{array}{c}\text { Diarrhea } \\
\text { Abdominal pain } \\
\text { Weight loss }\end{array}$ & Normal & $\begin{array}{l}\text { AGA 1/68 } \\
\text { AEM 1/320 } \\
\text { AR 1/320 }\end{array}$ & DQ2 (+) & $\begin{array}{c}\text { Moderate atrophy } \\
(3 \mathrm{~b})\end{array}$ \\
\hline Father & $41 / M$ & Asymptomatic & Normal & $\begin{array}{c}\text { AGA } 42 \\
\text { AEM 1/320 }\end{array}$ & DQ2 (+) & $\begin{array}{l}\text { Moderate atrophy } \\
\qquad(3 b)\end{array}$ \\
\hline Mother & $42 / F$ & Asymptomatic & Ferropenia & $\begin{array}{l}\operatorname{AGA}(-) \\
\operatorname{AEM}(-)\end{array}$ & DQ2 (+) & $\begin{array}{l}\text { Submucosal infl. } \\
\text { infiltrate (2) }\end{array}$ \\
\hline
\end{tabular}

M: male; F: female; AGA: anti-gliadin Ab; AEM: anti-endomysium Ab; AR: anti-reticulin Ab 
showed that the prevalence of this association is $7 \%$, and the diagnosis of type- 1 diabetes mellitus at an early age ( $<4$ years), and the fact of being female, are associated with a greater risk of having both diseases. Several studies also exist that had conflicting results regarding whether the early diagnosis of $\mathrm{CD}$ and the starting of a GFD prevents the development of other diseases with an immunological basis $(11,12)$.

In our family, the younger sister was diagnosed at 1.5 years of age with CD, and in spite of a strict GFD she developed type- 1 diabetes mellitus after 5 years. All members of this family were HLA-DQ2 (+), and -as is well known- this is a gene not only closely related to the development of $\mathrm{CD}$, but also to the development of type- 1 diabetes mellitus (13).

An increased risk of developing malignant neoplasms such as cholangiocarcinoma exists in patients with PSC, and a higher incidence of colon cancer develops in patients with ulcerous pancolitis, especially in cases with severe acute onset, standing for more than 10 years, although recent studies showed a possible prevention of colon cancer in patients treated with ursodeoxycholic acid in the long term (14).

Although the familiar aggregation of CD is $10-20 \%$, in our case all members were affected, two of them with a diagnosis during infancy and with associated diseases, while the parents were diagnosed with silent forms of CD through a family study, and had a good response to GFD (15).

It is important therefore to routinely carry out a family study before making a diagnosis of $\mathrm{CD}$, for the diagnosis of new cases -even if asymptomatic from GFD onset- may prevent the development of complications, and probably the appearance of associated diseases.

\section{REFERENCES}

1. Collin P, Kaukinen K, Välimäki M, Salmi J. Endocrinological disorders in celiac disease. Endocrine Reviews 2002; 23: 464-83.

2. Zone JJ. Skin manifestations of celiac disease. Gastroenterology 2005; 128 (Supl. 1): S87-91.

3. Hakanen M, Luotola K, Salmi J, et al. Clinical and subclinical autoimmune thyroid disease in adult celiac disease. Dig Dis Sci 2001; 46: $2631-5$.

4. Mac Faul GR, Chapman RW. Sclerosing cholangitis. Curr Op Gastroenterol 2004; 20: 275-80.

5. Smyth C, Kelleher D, Keeling PW. Hepatic manifestations of gastrointestinal diseases. Inflammatory bowel disease, celiac disease and Whipple's disease. Clin Liver Dis 2002; 6: 1013-32.

6. Volta U, Rodrigo L, Granito A, et al. Celiac disease in autoimmune cholestatic liver disorders. Am J Gastroenterol 2002; 97: 2609-13.

7. Harbior A, Rawa T, Orlowska J, et al. Association of primary sclerosing cholangitis, ulcerative colitis and coeliac disease in female siblings. Eur J Gastroenterol Hepatol 2002; 14: 787-91.

8. Wurm P, Dixon AD, Rathbone BJ. Ulcerative colitis, primary cholangitis and coeliac disease: two cases and review of the literature. Eur J Gastroenterol Hepatol 2003; 15: 815-7.

9. Ventura A, Magazzu G, Greco L. Duration of exposure to gluten and risk for autoimmune disorders in patients with celiac disease. Gastroenterology 1999; 117: 297-303.

10. Sategna C, Solerio E, Scaglione N, et al. Duration of gluten exposure in adult celiac disease does not correlate with the risk for autoimmune disorders. Gut 2002; 49: 502-5.

11. Cerruti F, Bruno G, Chiarelli F, et al. Younger age at onset and sex predict celiac disease in children and adolescents with type 1 diabetes. Diabetes Care 2004; 27: 1294-8.

12. Biagi F, Pezzimenti D, Campanella J, et al. Gluten exposure and risk of autoimmune disorders. Gut 2002; 50: 140-1.

13. Doolan A, Donaghue K, Fairchild J, Wong M, Williams AJ. Use of HLA typing in diagnosing celiac disease in patients with type 1 diabetes. Diabetes Care 2005; 28: 806-9.

14. Pardi DS, Loftus EV Jr, Kremers WK, Keach J, Lindor KD. Ursodeoxycholic acid as a chemopreventive agent in patients with ulcerative colitis and primary sclerosing cholangitis. Gastroenterology 2003; 124: 889-93.

15. Rodrigo L, Riestra S, Fuentes D, González S, López-Vázquez A, López-Larrea C. Diversas formas clínicas de presentación de la enfermedad celíaca dentro de la misma familia. Rev Esp Enferm Dig 2004; 96: 612-9. 